\title{
Health related quality of life among children with Type I diabetes, Assiut city, Egypt
}

\author{
Marzoka A. Gadallah ${ }^{* 1}$, Taghreed Abdul-Aziz M. Ismail ${ }^{2}$, Naglaa Saad Abdel Aty ${ }^{3}$ \\ ${ }^{1}$ Pediatric dept., Faculty of Nursing, Assiut University, Assiut, Egypt \\ ${ }^{2}$ Public health \& community medicine dept., Faculty of medicine, Assiut University, Assiut, Egypt \\ ${ }^{3}$ Community health nursing dept., Nursing, Faculty of Nursing, Assiut University, Assiut, Egypt
}

Received: March 10, 2017

DOI: $10.5430 /$ jnep.v7n10p73
Accepted: May 1, 2017

URL: https://doi.org/10.5430/jnep.v7n10p73

\begin{abstract}
Objective: Health related quality of life (HRQOL) is a multidimensional construct that includes physical and psychosocial functioning, has emerged as an important outcome in pediatric population with chronic health conditions. The study objectives are to measure the quality of life among children with type I diabetes compared to healthy peers and to determine factors affecting the QOL among children with type I diabetes.

Methods: Analytic cross sectional study was conducted in Sidi Galal health insurance outpatient clinic for children with type 1 diabetes mellitus and a comparison group of healthy peers was taken from other outpatient clinics. A total of four hundred and twelve children, aged from 8-18 years with type 1 diabetes and four hundred and twelve healthy peers matched in age and sex were interviewed. Three tools were used for this study: Demographic questionnaire, Socio-economic scale, and Peds QL4.0 Generic Core Scale was used to measure HRQOL.

Results: The mean age of studied children was $12.9 \pm 3.2$. More than $60 \%$ of children with diabetes had uncontrolled glycemic level and $60 \%$ of them were in low socio-economic level. Children with diabetes had significantly lower HRQOL than healthy children in all domains. Age, glycemic control status and birth order of the diabetic children showed no significance difference regarding the QOL. Disease duration affected only the emotional function of the QOL and females showed significantly higher score regarding school functioning. Social, school and the total QOL scores were significantly higher among children with highly educated mothers while father's education affected the emotional, school and total QOL scores. Children in the middle and high social class showed significantly higher scores regarding social, school and total QOL. Presence of diabetic parent positively affected the social functioning while had negative effect on the school function of children with type I diabetes.

Conclusions and recommendations: Diabetes is negatively affecting all the QOL functioning of the children. We recommend that Integrated programs between child's home, school and health insurance clinics for educating and supporting children with diabetes to improve their HRQOL.
\end{abstract}

Key Words: Health-related quality of life, Children, adolescent, Type I diabetes mellitus

\section{INTRODUCTION}

Diabetes is a global epidemic with 382 million people affected by the disease worldwide and with figures expected to rise to 582 million by 2035. ${ }^{[1]}$ Type 1 diabetes melli- tus (T1DM) is one of the most common chronic diseases, affecting 1 in every 400-600 children and adolescents. ${ }^{[2]}$

Six countries in the Middle East and North African (MENA) Region are among the world's 10 highest for diabetes preva-

\footnotetext{
*Correspondence: Marzoka A. Gadallah; Email: marzoka_abdelazez@yahoo.com; Address: Pediatric dept., Faculty of Nursing, Assiut University, Assiut, Egypt.
} 
lence. These countries are Bahrain, Egypt, Kuwait, Oman, Saudi Arabia and United Arab Emirates. ${ }^{[3]}$ Among Eastern Mediterranean and Middle Eastern countries, as well as MENA region, the largest contribution to the total number of estimated childhood TIDM cases comes from Egypt which accounts for about a quarter of the region's total. ${ }^{[4]}$ The incidence varies between 1/100,000 per year (Pakistan) and $8 / 100,000$ per year (Egypt). ${ }^{[5]}$ and the prevalence was $12.6 \%$ among children under the age of 15 years as reported by Soltesz et al. ${ }^{[6]}$

Simply surviving a long term illness is not sufficient; the quality of survival for chronically ill children is a fundamental focus of comprehensive healthcare. ${ }^{[7]}$

Quality of life (QOL) is considered as an important indicator of the outcome of treatments that refers to child's well-being and functioning. It can be used to describe the impact of the health condition on the child as well as the effects of treatment strategies. ${ }^{[8]}$

Diabetes Mellitus is accounting for more hospitalizations in children than any other chronic illness. Moreover, diabetes causes children and adolescents to miss school and causes parents to miss days at work. ${ }^{[8]}$ So, it's crucial to study the QOL for children suffering from diabetes and to assess factors affecting their QOL.

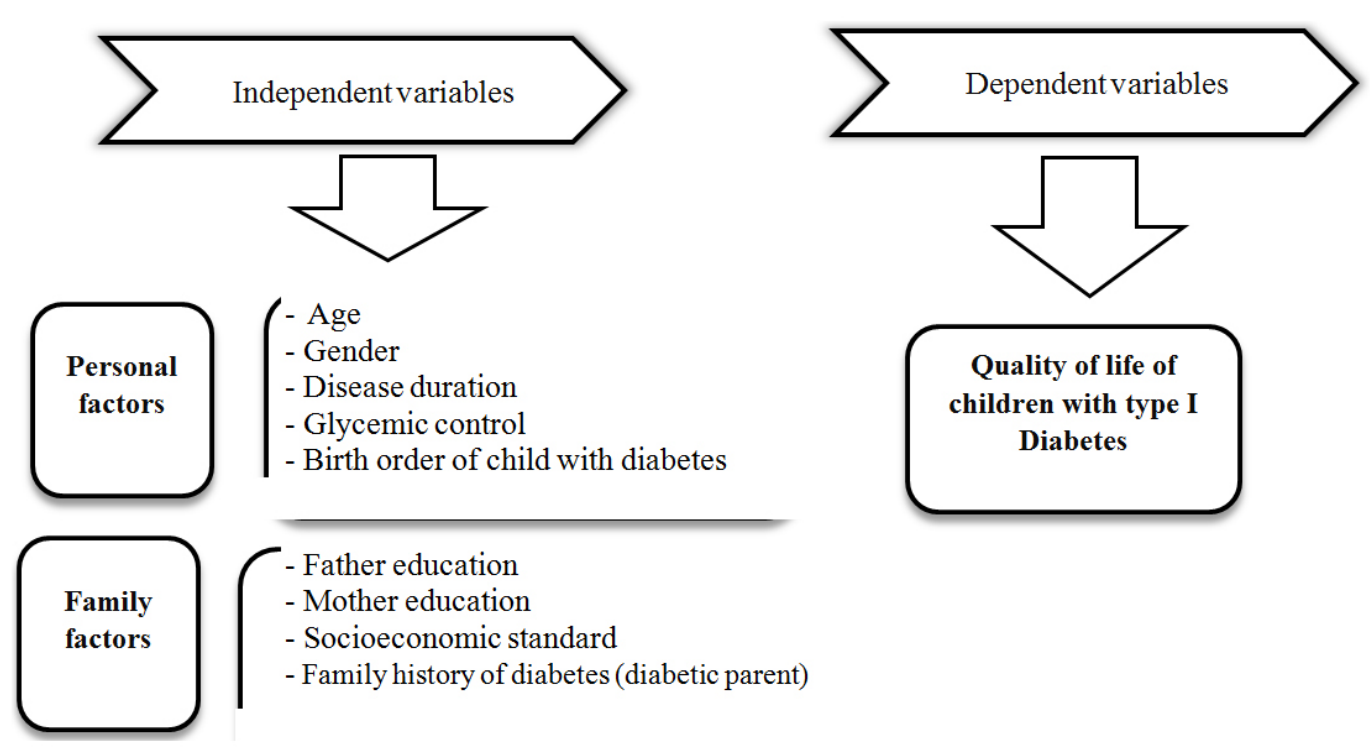

Moreover, Comparing the HRQOL scores between chronically ill children and healthy children is useful in understanding the relative clinical impact of different pediatric chronic health conditions on their HRQOL. ${ }^{\text {9] }}$

Trained pediatric nurses play a critical role in empowering children with diabetes to better manage diabetes through selfcare and improving the QOL of these children with diabetes through providing them and their families with the required information and consultations. ${ }^{[10]}$

\subsection{Study questions}

- Is the QOL of children with diabetes differing from that of healthy peers?

- What are the factors affecting the QOL of children and adolescents with diabetes?

\section{Conceptual framework}

Figure 1 shows the conceptual framework of this study.

\subsection{Study objectives}

- Assess the QOL among children with type I diabetes.

- Determine sociodemographic, family and disease related factors affecting the QOL among children with type I diabetes.

Figure 1. Conceptual framework

\section{Patients And method}

\subsection{Study design, setting and population}

Analytic cross-sectional study. The study was conducted in Sidi Galal health insurance outpatient clinics in Assuit city-Upper Egypt. The clinics provide all health insurance services for school students from different areas. Children with diabetes were among those attending diabetes outpatient clinic while their matched healthy peers were among those attended Sidi Galal outpatient dental and ophthalmology clinics and they are free from any chronic disease and they were asked about their HRQOL apart from the current acute con- 
dition, so their answers are related to their healthy life time. They were matched for children with type 1 diabetes mellitus regarding age and sex. Four hundred and twelve children with Type I diabetes mellitus who diagnosed more than 1 year and 412 healthy peers were included in the study.

\subsection{Exclusion criteria}

- Any student who had a history of any chronic disease (Rather than type I diabetes) were excluded from both the study groups.

- Children who were diagnosed with type I diabetes since less than 1 year.

\subsection{Data collection tools}

Three tools were used for this study:

Tool I: Demographic questionnaire which includes sociodemographic data: age, sex, birth order, disease duration, family history of diabetes.

Tool II: Socio Economic Status Scale: This scale was designed by Abd-El-Tawab (2004). ${ }^{[1]}$ To assess socioeconomic status of the family and consists of 4 dimensions, which include the following: Parent's level of education (8 items) - Parent's occupation (2 items) - Total family monthly income (6 items) - Life style of the family (3 items). The item of income had been modified by the researchers as following: according to the rate of inflation and increase to be conforming with recent income through comparing difference of the value of the golden pound at 2004 to that at 2015 and multiplying the rate of inflation to the income scale. Each item has one score; the total score was divided into three classes as high from $85 \%-100 \%$, moderate from $60 \%-84 \%$, low less than $60 \%$.

- Validity of tool II were assessed by 5 experts in pediatric nursing field and the content validity index was 0.88 .

- Reliability of tool II was assessed using alpha - Cronbach test to test the internal consistency $r=0.9$.

Tool III: The Pediatric Quality of Life Inventory (PedsQL) 4.0 Generic Core Scales ${ }^{[12]}$ was used to measure HRQOL. It is a 23-item, multidimensional quality-of-life instrument designed for use with children. Child self-report forms are available for age groups (5-7, 8-12, 13-18, and > 19 years). The two appropriate forms were used in the present study according to the child age (8-12 \& 13-18).

The PedsQL Generic Core Scales are easy to score. The items of the four Scales [Physical Functioning (8 items), Emotional Functioning, Social Functioning, and School Functioning (5

Published by Sciedu Press items for each)] are grouped together on the actual questionnaire, so it is easy to create scale Scores. On the PedsQOL Generic Core Scales, for ease of interpretability, items are reversed scored and linearly transformed to a 0-100 scale, so that higher scores indicate better HRQOL (Health-Related Quality of Life). To reverse score, transform the 0-4 scale items to 0-100 as follows: $0=100,1=75,2=50,3=25$, $4=0$. To create Scale Scores, the mean is computed as the sum of the items over the number of items. To create the Psychosocial Health Summary Score, the mean is computed as the sum of the items over the number of items in the Emotional, Social, and School Functioning Scales. To create the Total Scale Score, the mean is computed as the sum of all the items over the number of items on all the Scales.

- Acceptable levels of reliability and validity for the PedsQL have been reported in both healthy and chronically ill children. Cronbach reliability for PedsQL ${ }^{\mathrm{TM}}$ 4.0 Generic Core Scale ( $\alpha=0.87$ ) is very satisfactory. the Cronbach is equally high for all age groups $(\alpha$ $=0.88$ for $8-12 \mathrm{yr}$ old; and $\alpha=0.84$ for $13-18 \mathrm{yr}$ old). ${ }^{[12]}$

- The Arabic version of the PedsQL General scale Score showed sufficient feasibility, reliability and validity to be used for research purposes in public health setting for children 2-18 years old and their parents by Abdul-Rasoul et al. 2012. ${ }^{[13]}$ The instrument took approximately 10 minutes to be completed.

A pilot study was carried on $10 \%$ of the sample. It was conducted to assess clarity of the questions, the need for any rewording and/or rephrasing and time needed to fulfill the questionnaire. As the result of the pilot study, there was no modifications in the questionnaire which needed a total of 20-25 minutes to be completed depending on the response of the participants. Data of the pilot study were included in the study groups. Each child was interviewed individually during the waiting time. Glycemic control as determined by HbA1c was obtained from patients' record. The most recent HbA1c value, a standard measure of glycemic control over the prior 90 days. These HbA1c values were all obtained at the time of data collection. It was determined as either controlled (having HbA1c $<7.5 \%$ and uncontrolled if having $\mathrm{HbA} 1 \mathrm{c} \geq 7.5 \%){ }^{[14]}$

\subsection{Study period}

The study was conducted between September 2015 to May 2016.

\subsection{Ethical considerations}

- The study protocol was approved by the ethical committee of faculty of nursing, Assiut University. 
- An official permission was obtained from director of health insurance sector for Upper Egypt.

- The researchers assured voluntary participation and confidentiality of each child who agrees to participate in this study.

- Written consent was obtained from the caregiver for children below 12 years and from older children who attended the clinic alone.

\subsection{Data management and statistical analysis}

- Data were entered, cleaned and recoded (if needed) using the Statistical Package for Social Science (SPSS Inc., Chicago, IL, USA) version 20.

- Data analysis was done in the form of univariate analysis: descriptive statistics (frequency \& percent for qualitative data, mean $\pm \mathrm{SD}$ for quantitative data). Bivariate analysis: cross tabulation. Chi-square test $\left(\chi^{2}\right)$ was used to test the difference between the proportions of qualitative variables. Student $t$ test and Analysis of Variance (ANOVA test) were used to compare the mean of different groups.

- Statistical significance level was considered when $p<$ .05 for all statistical tests.

\section{RESUltS}

Males represented $47.1 \%$ of the studied group versus $52.9 \%$ for females. The mean age of the studied children with diabetes was $12.9 \pm 3.2$ years. About $60 \%$ of the children with diabetes were of low SE class versus $15.3 \%$ in the high SE class. Near half of the children (48.3\%) were the 2nd or third child in the family. Regarding the educational level, more than one third of the children's fathers (35.9\%) and more than half of the children's mothers $(53.9 \%)$ were illiterate while $15.8 \%$ of fathers and $11.4 \%$ of mothers had university or higher education (see Table 1)

Figure 2 shows that about $38.0 \%$ of children with diabetes were controlled versus $62.0 \%$ who were uncontrolled. The mean age for the diabetic group was $12.9 \pm 3.2$ versus 13.5 \pm 3.4 for healthy peers with no significant difference. All items of QOL: physical, emotional, social, school, psychosocial and total QL scores were lower among the diabetic group than the control group with very high statistical significant difference. The mean total QOL score was $70.9 \pm 13.3$ among the diabetic group versus $94.2 \pm 2.4$ for the healthy peers (see Table 2).

The QOL aspects showed no statistical significant difference regarding gender except school as females showed significantly higher score than males $(66.3 \pm 18.3$ versus $62.6 \pm$ 19.2 respectively). Age, glycemic control status and birth order of the children with diabetes showed no statistical significance difference regarding the QOL items (see Figure 3 ). Disease duration affected only the emotional function of the QOL as the mean emotional score was higher among children with type I diabetes for less than 5 years than those with disease duration for 5 years and more $(68.6 \pm 17.9$ versus $64.9 \pm 17.2$ respectively, $p=.03$ ). Other QOL functions showed no statistical significance difference regarding disease duration (see Table 3).

Table 1. Socio-demographic characteristics of children with diabetes

\begin{tabular}{lll}
\hline Variables & $\mathbf{N}=\mathbf{4 1 2}$ & Percentage (\%) \\
\hline Gender & 194 & 47.1 \\
Male & 218 & 52.9 \\
Female & $12.9 \pm 3.2$ & \\
Age (Mean \pm SD) & 183 & 44.4 \\
$8-<12$ years & 229 & 55.6 \\
$\quad \geq 12$ years & & \\
Socio-economic class & & 60.2 \\
Low & 248 & 24.5 \\
Middle & 101 & 15.3 \\
High & 63 & \\
Birth order & & 18.0 \\
1st child & 74 & 48.3 \\
2nd-3rd & 199 & 33.7 \\
4th or higher & 139 & \\
Father education & & 35.9 \\
Illiterate/read \& write & 148 & 18.2 \\
Primary/preparatory & 75 & 30.1 \\
$\quad$ Secondary education & 124 & 15.8 \\
$\quad$ University/higher & 65 & \\
Mother education & & 53.9 \\
Illiterate/read \& write & 222 & 14.3 \\
Primary/preparatory & 59 & 20.4 \\
Secondary education & 84 & 11.4 \\
University/higher & 47 & \\
\hline
\end{tabular}

As regards mother education, social, school and the total QOL scores were significantly higher among children with highly educated mothers (secondary, university and higher) than the lower educated mothers (Illiterate, read \& write, primary and preparatory education). Regarding father education, children whose fathers has university and higher education showed significantly higher scores for emotional, school and total QOL than those whose fathers had lower educational levels. Children in the middle and high social class showed significantly higher scores regarding social, school and total QOL than those in the low socioeconomic class. Children who had diabetic parent had significantly higher score in their social QOL, while on the contrary, they had significantly lower scores in their school related QOL items (see Table 4).

ISSN 1925-4040 E-ISSN 1925-4059 


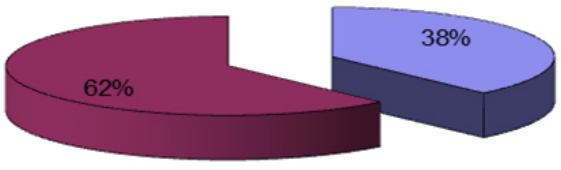

Figure 2. Distribution of children with type I diabetes according to glycemic control

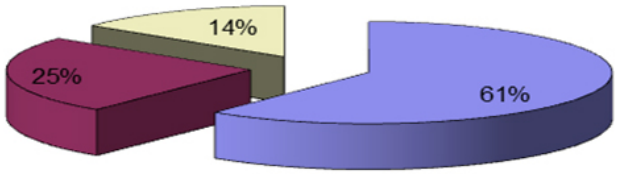

Figure 3. Distribution of children with type I diabetes according to the socioeconomic level

Table 2. Comparison between the diabetic group and healthy group regarding socio-demographic characteristics and QOL items

\begin{tabular}{lllll}
\hline Variables & Diabetic group (No = 412) & Healthy group (No = 412) & Statistical test & $\boldsymbol{p}$ \\
\hline Gender & & & \\
$\quad$ Male & $194(47.1 \%)$ & $194(47.1 \%)$ & $\chi^{2}=0$ & 1.00 \\
Females & $218(52.9 \%)$ & $218(52.9 \%)$ & & \\
Age & $12.9 \pm 3.2$ & $13.5 \pm 3.4$ & & .4 \\
Quality of life items & $($ Mean \pm SD) & & & \\
Physical quality & $70.2 \pm 14.5$ & $94.3 \pm 5.1$ & 19.4 & $<.0001$ \\
Emotional & $66.7 \pm 17.6$ & $91.6 \pm 7.5$ & 14.5 & $<.0001$ \\
Social & $78.3 \pm 18.8$ & $95.6 \pm 5.1$ & 12.6 & $<.0001$ \\
School & $90.8 \pm 7.6$ & 14.8 & $<.0001$ \\
Psychosocial & $74.6 \pm 18.8$ & $92.7 \pm 2.6$ & 25.6 & $<.0001$ \\
Total QL & $70.2 \pm 14.5$ & $94.2 \pm 2.4$ & 13.8 & $<.0001$ \\
\hline
\end{tabular}

\section{Discussion}

In the present study, the QOL scores were compared between children with type I diabetes children and healthy peers and the factors affecting the QOL in children with diabetes were investigated.

The present study reported that diabetes had a negative impact on all domains of HRQOL with mean scores of physical, emotional, social and school functioning were low with high statistical significant differences for children with diabetes compared to healthy peers as shown in Table $2(p<.0001$ for all domains). This result was similar to the work done by Varni et al. (2007) and Arabiat et al. (2013) $)^{[9,15]}$ who reported that children with chronic health condition had progressively lower HRQOL compared to their healthy peers. Also, Nuboer et al. $(2008)^{[16]}$ reported that children with diabetes had lower QOL compared to healthy children. 
Table 3. Quality of life items according to personal characteristics of children with type I diabetes

\begin{tabular}{|c|c|c|c|c|c|c|c|}
\hline \multirow{2}{*}{ Variables } & \multirow{2}{*}{$\mathbf{N}$} & \multicolumn{6}{|c|}{ Items of Quality of life } \\
\hline & & Physical & Emotional & Social & School & Psychosocial & Total \\
\hline \multicolumn{8}{|l|}{ Gender } \\
\hline Male & 194 & $69.6 \pm 14.9$ & $65.9 \pm 18.2$ & $78.4 \pm 18.1$ & $62.6 \pm 19.2$ & $69.6 \pm 14.9$ & $70.5 \pm 13.3$ \\
\hline Females & 218 & $70.8 \pm 14.2$ & $67.4 \pm 17.1$ & $78.3 \pm 19.5$ & $66.3 \pm 18.3$ & $70.8 \pm 14.2$ & $71.3 \pm 13.3$ \\
\hline$T$ test & & 0.8 & 0.8 & 0.03 & 2.0 & 0.8 & 0.6 \\
\hline$p$ & & .4 & .4 & .9 & .04 & .4 & .6 \\
\hline \multicolumn{8}{|l|}{ Age } \\
\hline $8-<12$ years & 183 & $70.0 \pm 15.8$ & $66.6 \pm 18.4$ & $76.9 \pm 20.6$ & $64.7 \pm 20.3$ & $70.0 \pm 15.8$ & $70.4 \pm 14.1$ \\
\hline$>12$ years & 229 & $70.4 \pm 13.5$ & $66.8 \pm 16.9$ & $79.5 \pm 17.2$ & $64.5 \pm 17.5$ & $70.4 \pm 13.5$ & $71.3 \pm 12.6$ \\
\hline$T$ test & & 0.3 & 0.09 & 1.4 & 0.1 & 0.3 & 0.7 \\
\hline$p$ & & .8 & .9 & .2 & .9 & .8 & .5 \\
\hline \multicolumn{8}{|c|}{ Glycemic control } \\
\hline Controlled & 157 & $70.0 \pm 14.0$ & $66.0 \pm 17.0$ & $79.3 \pm 17.1$ & $65.4 \pm 18.0$ & $70.0 \pm 14.0$ & $71.9 \pm 12.4$ \\
\hline Uncontrolled & 255 & $70.4 \pm 14.9$ & $67.1 \pm 18.0$ & $77.8 \pm 19.8$ & $64.1 \pm 19.2$ & $70.4 \pm 14.9$ & $70.3 \pm 13.8$ \\
\hline$T$ test & & 0.3 & 0.7 & 0.8 & 0.7 & 0.3 & 1.3 \\
\hline$p$ & & .7 & .5 & .4 & .5 & .8 & .2 \\
\hline \multicolumn{8}{|l|}{ Birth order } \\
\hline 1st child & 74 & $70.9 \pm 15.7$ & $68.5 \pm 18.0$ & $80.8 \pm 18.4$ & $67.8 \pm 18.7$ & $70.9 \pm 15.7$ & $71.5 \pm 13.7$ \\
\hline 2nd-3rd & 199 & $69.9 \pm 13.7$ & $66.6 \pm 17.3$ & $76.9 \pm 17.6$ & $65.0 \pm 18.2$ & $69.9 \pm 13.7$ & $70.9 \pm 12.7$ \\
\hline 4th or higher & 139 & $70.3 \pm 15.1$ & $65.8 \pm 17.8$ & $79.1 \pm 20.5$ & $62.3 \pm 19.4$ & $70.3 \pm 15.1$ & $70.7 \pm 014.0$ \\
\hline$T$ test & & 0.1 & 0.6 & 1.4 & 2.2 & 0.1 & 0.1 \\
\hline$p$ & & .9 & .6 & .3 & .1 & .9 & .9 \\
\hline \multicolumn{8}{|c|}{ Disease duration } \\
\hline$<5$ years & 198 & $71.0 \pm 14.9$ & $68.6 \pm 17.9$ & $77.4 \pm 19.1$ & $65.9 \pm 19.5$ & $71.0 \pm 14.9$ & $71.4 \pm 13.5$ \\
\hline$>5$ years & 214 & $69.5 \pm 14.2$ & $64.9 \pm 17.2$ & $79.2 \pm 18.5$ & $63.3 \pm 18.0$ & $69.5 \pm 14.2$ & $70.5 \pm 13.1$ \\
\hline$T$ test & & 1.0 & 2.2 & 1.0 & 1.4 & 1.0 & 0.7 \\
\hline$p$ & & .3 & .03 & .3 & .2 & .3 & .5 \\
\hline
\end{tabular}

Moreover, Kalyva et al. (2011) and Abdul-Rasoul et al. $(2013)^{[17,18]}$ reported that children with TIDM reported significantly lower total generic QOL than controls. The QOL scores were lower for physical and emotional domains. However, there was no difference in the school and social QOL scores between patients and controls.

The present study reported that the mean total QOL score was $70.9 \pm 13.3$ (see Table 2). HRQOL has been reported to range between 59.2 and 73.8 in other countries, with the lowest overall scores found in Iran and Greece, and the highest scores in Sweden, Italy and the US. The children with diabetes in Saudi Arabia reported lower individual and total scale (64.8) scores compared to children with diabetes in several other countries. ${ }^{[19]}$

Regarding physical functioning, the majority of children with diabetes had significantly lower physical functioning than healthy peers, this may be due to the developmental changes that occur as school-age children with type I diabetes grow in to adolescence, individual differences in caloric intake related to growth spurts and participation in sports, onset of menses in female adolescents, and adolescent mood swings are all factors contribute to the lower score of physical QOL among children with diabetes. ${ }^{[20]}$

Abdul-Rasoul et al. (2013) ${ }^{[18]}$ reported that children with TIDM had lower physical functioning than controls, they explained this result by the demands that diabetes puts on children and their parents to maintain good glycemic control.

The majority of children with diabetes had significantly more problems regarding emotional functioning than healthy peers; this may be explained by their worry about long term complications, future plans and financial costs of the treatment. This is conformed to the results reported by Al-Akour et al. (2010). ${ }^{[21]}$ The preoccupation of children and adolescents with TIDM with themes such as long-term complications of their chronic illness and their lack of autonomy may account for their lower emotional HRQOL. ${ }^{\text {[21-23] }}$

As regards school functions, there is no doubt that diabetes affects school functioning. The negative effect of diabetes on school function was reported in our study. This result is in 
agreement with Al-Akour et al. (2010) ${ }^{[21]}$ who reported that children with diabetes had low score in school QOL which may be due to repeated absences from school and recurrent hospitalization. Moreover, uncontrolled glycemic level con- tributes to neurophysiological changes. In addition, poorly controlled diabetes is associated with subtle neuropsychological deficits that may reduce academic achievement. ${ }^{[24]}$

Table 4. Quality of life items according to some family characteristics of children with type I diabetes

\begin{tabular}{|c|c|c|c|c|c|c|c|}
\hline \multirow{2}{*}{ Variables } & \multirow{2}{*}{$\mathbf{N}$} & \multicolumn{6}{|c|}{ Items of Quality of life } \\
\hline & & Physical & Emotional & Social & School & Psycho-social & Total \\
\hline \multicolumn{8}{|l|}{ Mother education } \\
\hline Illiterate/read \& write & 222 & $69.3 \pm 14.7$ & $66.3 \pm 17.8$ & $76.5 \pm 18.6$ & $62.3 \pm 18.2$ & $69.3 \pm 14.7$ & $69.4 \pm 13.5$ \\
\hline Primary/preparatory & 59 & $69.1 \pm 13.1$ & $65.9 \pm 16.9$ & $75.1 \pm 19.0$ & $64.7 \pm 18.4$ & $69.1 \pm 13.1$ & $70.4 \pm 10.8$ \\
\hline Secondary education & 84 & $72.1 \pm 15.2$ & $65.8 \pm 18.1$ & $84.5 \pm 17.2$ & $68.8 \pm 18.8$ & $72.1 \pm 15.2$ & $73.0 \pm 14.0$ \\
\hline University/higher & 47 & $72.7 \pm 14.1$ & $71.1 \pm 16.1$ & $80.1 \pm 20.0$ & $67.7 \pm 20.6$ & $72.7 \pm 14.1$ & $74.9 \pm 12.7$ \\
\hline F test & & 1.4 & 1.1 & 4.5 & 2.9 & 1.4 & 3.2 \\
\hline$p$ & & .3 & .3 & .004 & .03 & .3 & .02 \\
\hline \multicolumn{8}{|l|}{ Father education } \\
\hline Illiterate/read \& write & 148 & $69.0 \pm 13.9$ & $66.8 \pm 16.9$ & $76.5 \pm 18.7$ & $61.9 \pm 17.5$ & $69.0 \pm 13.9$ & $68.8 \pm 12.4$ \\
\hline Primary/preparatory & 75 & $70.2 \pm 13.8$ & $65.7 \pm 16.9$ & $78.1 \pm 17.8$ & $64.0 \pm 18.9$ & $70.2 \pm 13.8$ & $70.3 \pm 13.3$ \\
\hline Secondary education & 124 & $69.2 \pm 15.2$ & $63.8 \pm 18.4$ & $78.7 \pm 18.1$ & $65.4 \pm 19.3$ & $69.2 \pm 15.2$ & $71.1 \pm 13.6$ \\
\hline University/higher & 65 & $74.8 \pm 14.9$ & $72.9 \pm 17.2$ & $82.2 \pm 21.1$ & $69.9 \pm 19.6$ & $74.8 \pm 14.9$ & $76.1 \pm 13.4$ \\
\hline F test & & 2.7 & 4.0 & 1.4 & 2.9 & 2.7 & 4.8 \\
\hline$p$ & & .05 & .008 & .2 & .04 & .05 & .003 \\
\hline \multicolumn{8}{|l|}{ Social class } \\
\hline Low & 248 & $68.9 \pm 14.0$ & $65.5 \pm 17.1$ & $76.3 \pm 18.7$ & $62.1 \pm 17.6$ & $68.9 \pm 14.0$ & $69.4 \pm 12.9$ \\
\hline Middle & 101 & $72.5 \pm 14.5$ & $67.2 \pm 19.0$ & $81.2 \pm 17.4$ & $67.5 \pm 20.0$ & $72.5 \pm 14.5$ & $72.7 \pm 13.3$ \\
\hline High & 63 & $70.2 \pm 14.5$ & $70.4 \pm 16.9$ & $81.6 \pm 20.6$ & $69.5 \pm 19.8$ & $71.8 \pm 16.2$ & $74.3 \pm 14.0$ \\
\hline F test & & 2.7 & 2.0 & 3.6 & 5.7 & 2.7 & 4.7 \\
\hline$p$ & & .07 & .1 & .03 & .004 & .07 & .01 \\
\hline \multicolumn{8}{|c|}{ Presence of diabetic parent } \\
\hline Yes & 55 & $70.8 \pm 13.5$ & $68.0 \pm 15.7$ & $83.6 \pm 15.6$ & $59.2 \pm 20.2$ & $70.8 \pm 13.5$ & $71.5 \pm 13.4$ \\
\hline No & 357 & $70.1 \pm 14.7$ & $66.5 \pm 17.9$ & $77.5 \pm 19.1$ & $65.4 \pm 18.4$ & $70.1 \pm 14.7$ & $70.8 \pm 13.3$ \\
\hline$T$ test & & 0.3 & 0.6 & 2.6 & 2.2 & 0.3 & 0.3 \\
\hline$p$ & & .7 & .5 & .01 & .03 & .7 & .7 \\
\hline
\end{tabular}

Regarding the compromised social life reported in the present study among diabetic children and adolescence, this may indicate that social support from the family, peers and school personnel is lower than what those children with diabetes need and it highlights the importance of educational social programs about supporting children with diabetes.

This finding is contrary to Abdul-Rasoul et al. (2013) ${ }^{[18]}$ in Kuwait and Kalyva et al. (2011) ${ }^{[17]}$ in Greece who reported that children and adolescents with TIDM did not report compromised social HRQOL. This difference may be explained by differences in the cultural context and the way the community deal and support the chronically ill children including diabetics.

The present study reported that gender had no significant effect on any of the QOL aspects except for the school functions where females reported significantly higher score. This Published by Sciedu Press may be due to Egyptian community, especially upper Egypt that don't give enough degree of freedom for females so they spend most of their times in studying, in addition to the preoccupation of males with other social activities. Also some other researchers did not find any relationship between gender and QOL. ${ }^{[15,21,25]}$

Vanelli et al. (2003) ${ }^{[26]}$ reported that the impact of diabetes was similar for both boys and girls. In addition, Baş et al. $(2011)^{[27]}$ also reported no gender-related difference in the QOL scores between the study groups.

On the contrary, Abdul-Rasoul et al. (2013) ${ }^{[18]}$ reported that male gender predicted better QOL, as girls have been shown to have more diabetes-related worries which is conformed to the results of AlBuhairan et al. (2016) ${ }^{[19]}$ While Monazea et al. (2012) $)^{[28]}$ reported that female children with diabetes had total score QOL less than males but with no significant 
difference.

Our study revealed that, age had no effect on any of the QOL items. This is in agreement with Monazea et al. (2012) ${ }^{[28]}$ in the same community. Also Laffel et al. (2003), ${ }^{[25]}$ and Vanelli et al. (2003) ${ }^{[26]}$ reported no effect of age or the duration of diabetes regarding the QOL. While in the contrary, Abdul-Rasoul et al. (2013) ${ }^{[18]}$ and AlBuhairan et al. $(2016)^{[19]}$ reported that age of the patient was an important predictor of QOL as children got older, the scores improved.

In the present study, we reported that the controlled group represented $38.0 \%$ while $62.0 \%$ were uncontrolled. Abolfotouh et al. (2011) ${ }^{[29]}$ in Alexandria, Egypt reported that about three-quarters $(74.8 \%)$ of adolescents had uncontrolled glucose levels according to the HbA1c level, and only $25.2 \%$ were controlled. We reported no significant difference of the QOL scores of children with diabetes according to metabolic control levels. This is the same reported by Laffel et al. (2003), Baş et al. (2011) and Emmanouilidou et al. (2008). ${ }^{[25,27,30]}$

Moreover, Farrag et al. (2016) ${ }^{[31]}$ reported that uncontrolled diabetes did not affect Peds QOL except for school function domain, but with insignificant statistical level.

Our results are contradictory to that reported by Abolfotouh et al. $(2011)^{[29]}$ in Alexandia, Egypt.

El-Laboudy and Ramy (2006) ${ }^{[32]}$ revealed that poorly controlled group of children with diabetes experienced the worst QOL and the well-controlled group with tight glycemic control receiving intensive insulin therapy and kept on frequent home monitoring of blood glucose experienced higher worry and anxiety module scores than the fairly-controlled patients with a subsequent negative impact on the QOL also. So this observation highlights the need for balanced approach aiming for acceptable intermediate control so that, the intensive treatment, strict regime and the dietary restrictions would not affect the QOL. However, the relationship between QOL and metabolic control, measured by HbA1c is conflicting. Whittemore and Urban (2003) ${ }^{[33]}$ recommended that psychological outcome and QOL indicators must be considered separately from the metabolic treatment goals in type 1 diabetes.

Birth order of the child showed no effect on the QOL in the present study. This can be explained by the Arab and Egyptian culture which give care and attention to the sick child regardless of his birth order.

Our study reported no significant difference in the QOL regarding disease duration except in the emotional function as it was higher among children with disease duration less than
5 years. This finding may be due to more worries among persons with long disease duration about their future or the development of diabetes complications. The same finding was reported in many other studies. ${ }^{[25-27,33,34]}$

On the contrary, Monazea et al. (2012) ${ }^{[28]}$ reported that Adolescents with diabetes duration for 1-5 years had a higher QOL score than whose with duration $>5$ years. This finding is conformed to our study regarding the emotional function only.

Our study reported that both mother education as well as the socioeconomic class affected the social, school and total QOL functions. Also father education affected the emotional, school and total QOL functions. However, the three items are interrelated as both father and mother educations were represented in determining the socioeconomic class. However, Naughton et al. (2008) ${ }^{[34]}$ reported that parent education, was not significant predictors of overall HRQOL in their sample. Many studies didn't report relation between the socioeconomic level and the QOL among children with diabetes. ${ }^{[25,28]}$

The effect of socioeconomic level in the present study may be due the extra-care and management, type of treatment and also more support in all aspects including reinforcing the school functions that needs financial support which cannot be offered by the poor families (low socioeconomic level) and so it was reflected on the QOL scales.

Presence of one or more diabetic parent positively affected the social domain while negatively affected the school function of the QOL scale in the present study. Better social function may be due to the less psychological trauma and better coping strategies with the disease among persons with diabetic parent while the low school function may be interpreted by the negative effect of absenteeism, lack of external support of the school function due to more financial burden.

\section{Conclusion}

Children with diabetes had significantly lower HRQOL than healthy children in all domains. Age, glycemic control status and birth order of the children with diabetes showed no significance difference regarding the QOL. Disease duration affected only the emotional function of the QOL and females showed significantly higher score regarding school functioning. Social, school and the total QOL scores were significantly higher among children with highly educated mothers while father's education affected the emotional, school and total QOL scores. Children in the middle and high social class showed significantly higher scores regarding social, school and total QOL. Family history of diabetes affected the social and school functioning. 


\section{Recommendations}

(1) Assessing children with diabetes for detecting any problems that could affect their HRQOL should be included in diabetes management protocols.

(2) Integrated programs between child's home, school and health insurance clinics for educating and supporting children with diabetes to improve their HRQOL.

\section{CONFLICTS OF INTEREST Disclosure}

The authors declare that there is no conflict of interest.

\section{REFERENCES}

[1] Guariguata L, et al. Global estimates of diabetes prevalence for 2013 and projections for 2035. Diabetes Research and Clinical Practice. 2014; 103(2): 137-149. Available from: http://www.ncbi .nlm.nih.gov/pubmed/24630390 [Accessed February 12, 2017]. PMid:24630390 https://doi.org/10.1016/j.diabres . 2013 .11 .002

[2] Roze S, et al. Health-economic comparison of continuous subcutaneous insulin infusion with multiple daily injection for the treatment of Type 1 diabetes in the UK. Diabetic medicine: a Journal of the British Diabetic Association. 2005; 22(9): 1239-1245.

[3] International Diabetes Federation. Idf Diabetes Atlas. 2015. Available from: http://www.diabetesat las.org/resources/2015-atlas.html\%5Cnhttps: //www.idf.org/sites/default/files/EN_6E_Atlas_ Full_0.pdf\%Cnwww. ecuadorencifras.gob.ec

[4] International Diabetic Foundation. Diabetes at a glance. 2012,

[5] El-Ziny M, et al. Epidemiology of childhood type 1 diabetes mellitus in Nile Delta, northern Egypt-a retrospective study. Journal of Clinical Research in Pediatric Endocrinology. 2014; 6(1): 915. Available from: http://www.ncbi.nlm.nih.gov/pubmed/ 24637304 [Accessed February 12, 2017]. PMid:24637304 https: //doi.org/10.4274/Jcrpe. 1171

[6] Soltesz G, Patterson C, Dahlquist G. Diabetes in the Young: a Global Perspective. Global Trends in Childhood Type 1 Diabetes. 2009.

[7] Varni JW, Burwinkle TM, Lane MM. Health-related quality of life measurement in pediatric clinical practice: An appraisal and precept for future research and application. Health and Quality of Life Outcomes. 2005; 3: 34-43. PMid:15904527 https://doi.org/10.1 186/1477-7525-3-34

[8] Tantawi R, Amin FM, Fakhry SF. Quality of Life for Children Suffering from Diabetes Mellitus. 2015; 4(3): 2013-2016.

[9] Varni JW, Limbers CA, Burwinkle TM. Impaired health-related quality of life in children and adolescents with chronic conditions: a comparative analysis of 10 disease clusters and 33 disease categories/severities utilizing the PedsQL 4.0 Generic Core Scales. Health and Quality of Life Outcomes. 2007; 5: 43. Available from: http://www.ncbi.nlm.nih.gov/pubmed/17634123 [Accessed February 6, 2017]. PMid:17634123 https ://doi .org/10.1186/ 1477-7525-5-43

[10] Fireman B, Bartlett J, Selby J. Can disease management reduce health care costs by improving quality? Health Aff. 2004; 23: 63-75. https://doi.org/10.1377/hlthaff.23.6.63

[11] Abed El-Tawab: Socioeconomic status scale, Faculty of education, department of psychology. Assiut University. 2004.

[12] Varni JW, Seid M, Kurtin PS. PedsQL 4.0: reliability and validity of the Pediatric Quality of Life Inventory version 4.0 generic core scales in healthy and patient populations. Medical Care. 2001; 39(8): 800-12. Available from: http://www.ncbi.nlm.nih.gov/pub med/11468499 [Accessed February 14, 2017]. PMid:11468499 https://doi.org/10.1097/00005650-200108000-00006
[13] Abdul-Rasoul M, et al. Reliability and validity of the Arabic version of the PedsQL TM 4.0 generic ore scales and PedsQL TM 3.0 diabetes module. Journal of Diabetes Mellitus. 2012; 2(3): 301-307. https://doi.org/10.4236/jdm.2012.23047

[14] kim W, Hong JP, Ho Yoo J. Emotional and Behavioral Problems and Glycemic Control in Adolescents with Type 1 and Type 2 Diabetes. Journal of Psychiatry. 2017; 18(2): 1-5.

[15] Arabiat DH, Jabery MA. Health related quality of life in paediatric chronic health conditions: A comparative study among children and adolescents in Jordan. 2013; 5(11): 19-24.

[16] Nuboer R, et al. Effects of insulin pump vs. injection treatment on quality of life and impact of disease in children with type 1 diabetes mellitus in a randomized, prospective comparison. Pediatric Diabetes. 2008; 9(4pt1): 291-296. Available from: http: //www.ncbi.nlm.nih.gov/pubmed/18466210 [Accessed February 12, 2017]. PMid:18466210 https://doi.org/10.1111/j.13 $99-5448.2008 .00396 . x$

[17] Kalyva E, et al. Health-related quality of life (HRQoL) of children with type 1 diabetes mellitus (T1DM): self and parental perceptions. Pediatric Diabetes. 2011; 12(1): 34-40. Available from: http://www.ncbi.nlm.nih.gov/pubmed/20546163 [Accessed February 5, 2017]. PMid:20546163 https://doi.org/10.1111/ j.1399-5448.2010.00653.x

[18] Abdul-Rasoul M, et al. Quality of life of children and adolescents with type 1 diabetes in Kuwait. Medical Principles and Practice: International Journal of the Kuwait University, Health Science Centre. 2013; 22(4): 379-84. Available from: http://www.ncbi.nlm.nih .gov/pubmed/23428425 [Accessed November 21, 2016].

[19] AlBuhairan F, et al. Health related quality of life and family impact of type 1 diabetes among adolescents in Saudi Arabia. Diabetes Research and Clinical Practice. 2016; 114: 173-179. PMid:26830857 https://doi.org/10.1016/j.diabres.2016.01.001

[20] Faulkner MS, Chang L. Metabolic Control in School-Age Children and Adolescents with Type 1 Diabetes. 2007; 22(1).

[21] Al-Akour N, Khader YS, Shatnawi NJ. Quality of life and associated factors among Jordanian adolescents with type 1 diabetes mellitus. Journal of Diabetes and its Complications. 2010; 24(1): 43-47. Available from: http://linkinghub.elsevier. com/re trieve/pii/S1056872709000440 [Accessed February 5, 2017]. PMid:19464929 https://doi.org/10.1016/j.jdiacomp. 200 8.12 .011

[22] Wake M, Hesketh K, Cameron F. The Child Health Questionnaire in children with diabetes: cross-sectional survey of parent and adolescent-reported functional health status. Diabetic Medicine: a Journal of the British Diabetic Association. 2000; 17(10): 700-7. Available from: http://www.ncbi.nlm.nih.gov/pubmed/1111 0502 [Accessed February 5, 2017].

[23] Gardner N. Emotional and behavioural difficulties in children with diabetes: a controlled comparison with siblings and peers. Child: Care, Health and Development. 1998; 24(2): 115-28. Available from: http://www.ncbi.nlm.nih.gov/pubmed/954444 
1 PMid:9544441 https ://doi.org/10.1046/j.1365-2214.19 $98.00042 . \mathrm{x}$

[24] Northam EA, et al. Neuropsychological profiles of children with type 1 diabetes 6 years after disease onset. Diabetes Care. 2001; 24(9): 1541-6. Available from: http://www.ncbi.nlm.nih.gov/pubme d/11522696 PMid:11522696 https ://doi.org/10.2337/diac are.24.9.1541

[25] Laffel LMB, et al. General Quality of Life in Youth With Type 1 Diabetes Relationship to patient management and diabetes-specific family conflict. 2003.

[26] Vanelli M, et al. Relationship between metabolic control and quality of life in adolescents with type 1 diabetes. Report from two Italian centres for the management of diabetes in childhood. Acta bio-medica: Atenei Parmensis. 2003; 74 (Suppl 1): 13-17. Available from: http://www.ncbi.nlm.nih.gov/pubmed/128177 95 [Accessed January 29, 2017].

[27] Baş VN, et al. Diabetes \& Metabolism Evaluation of Factors Affecting Quality of Life in Children with Type 1 Diabetes Mellitus. 2011; 2(8).

[28] Monazea E, et al. Quality of Life Among Adolescents with Type I Diabetes Mellitus in Assiut. 2012; 80(1): 261-270.

[29] Abolfotouh MA, et al. Quality of life and glycemic control in adolescents with type 1 diabetes and the impact of an education inter- vention. International journal of general medicine. 2011; 4: 14152. Available from: http://www.ncbi.nlm.nih.gov/pubmed/ 21475630 [Accessed January 29, 2017]. PMid:21475630 https : //doi.org/10.2147/IJGM.S16951

[30] Emmanouilidou E, Karavatos A. Quality of life of children and adolescents with diabetes of Northern Greek Origin. 2008; 168-175. PMid: 18923667

[31] Farrag S, et al. World Nursing 2016 Quality of life and self-esteem of Egyptian children with type I Diabetes. J Nurs Care. 2016; 5(54). https://doi.org/10.4172/2167-1168.C1.020

[32] El-Laboudy, Ramy H. Emotional Disturbances and Quality of Life in Type-1 Diabetic Children and Adolescents: Relation to Glycemic Control and Microvascular Complications. 2006; 13(1): 80-93.

[33] Whittemore R, Urban A. Quality of life in school-aged children with type 1 diabetes on intensive treatment and their parents. The Diabetic Educator. 2003; 29(5): 847-54

[34] Naughton MJ, et al. Health-related quality of life of children and adolescents with type 1 or type 2 diabetes mellitus: SEARCH for Diabetes in Youth Study. Archives of Pediatrics \& Adolescent Medicine. 2008; 162(7): 649-657. Available from: http: //search.ebscohost. com/login. aspx?direct=true\&db=c8

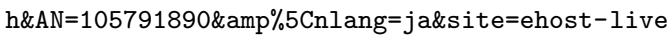

